\title{
Production Analysis and Scientific Mapping on Active Methodologies in Web of Science
}

\author{
https://doi.org/10.3991/ijet.v15i20.15619 \\ M Elena Parra-González; Adrián Segura-Robles; \\ Manuel-Ricardo Vicente-Bújez; Jesús López-Belmonte ( $\left.{ }^{\varpi}\right)$ \\ Universidad de Granada, Granada, España \\ jesuslopez@ugr.es
}

\begin{abstract}
Teaching and teaching trends are in continuous transformation. Teachers play new roles in the teaching and learning processes. This situation implies the need for new competencies, knowledge, and skills in teachers to carry out their tasks, thus adjusting them to the requirements of contemporary society. The incidence of technology and new training resources has led to an increase in innovative practices in learning situations. The purpose of this study is to analyze the production of active methodologies in the Web of Science database. The aim of it is to determine the state of the art within the scientific literature from a bibliometric perspective. In addition to the study of the main indicators of bibliometric production, a word analysis has been carried out. 2208 documents have been analyzed to achieve this. The study was carried out with the SciMAT software. The results reveal that scientific production has been increasing. The publications are mainly in English with a wide variety of topics, outstanding among them Higher Education in the early years. The study concludes that the research has specialized in topics such as the active profile of students and the influence of innovative practices on the learning process.
\end{abstract}

Keywords-Bibliometric analysis, scientific production, active methodologies, scientific mapping, SciMAT.

\section{Introduction}

The society of the 21 st century is immersed in a whirlwind of changes and facing a profound transformation as a result of social advances and technologies derived from our global and multicultural system having a direct impact on our lives [1]. In this context, institutions also evolve, and among these, our educational system. A system that, as we currently know it, is structured as a complex reality (both in its organization and in its operation) in which many socio-cultural factors have an interrelated impact that, in turn, have a very direct impact on classroom work [2].

The school is immersed in continuous changes to respond to the new demands that are demanded from contemporary society. School agents need to become aware of its protagonist and social importance. This favors the training of new generations in problem-solving, teamwork and it adapts to the global and technological world in 
which it operates, demanding from teachers its talent to evolve, to learn and use its competences in the reformulation of the teaching function [3]. The teacher becomes the central axis of this reality since it is increasingly obvious that education professionals must be able to design tasks and learning situations that make it possible to solve problems, apply learned knowledge and stimulate learning of student activity [4]. In their daily practice, the teacher is not only required knowledge related to the different areas of the curriculum (linguistics, mathematics, art, etc.). Teachers are the mastery of a series of skills and abilities (handling of new technologies, good disposition, and capacity for teamwork, etc.) that lead him to implement in his classes an original and attractive methodology. These methodologies should awaken the motivation of the student and allows him to build his own knowledge, giving the latter a more active, responsible, and autonomous role in the teaching-learning process [5].

Thus, for [6] success in reinventing educational systems worldwide will depend on the transformation of both pedagogical and methodological processes and the redesign of learning tasks so that these should not only be limited to school, but must encompass peer learning, intergenerational collaboration, and community relations. In addition, information and communication technologies (ICT) can be used to support efforts for pedagogical and methodological transformation. Still, it is essential to recognize that 21 st-century learning experiences must incorporate more than just technology [7].

The role of teachers should no longer be, therefore, the mere transmission of a series of objectives and contents, but rather that of interacting with the social and cultural environment in which they carry out their activity [8]. Having teachers who know and apply new work methodologies helps to accept situations that, in traditional teaching, from literacy and passive listening, leave out of the teaching-learning process for students who present problems in reading or writing comprehension like this as well as students with diversity [9]. In this sense, all countries aspire to have responsible teachers, passionate about their profession, competent, well trained, and willing to update this training in emerging methodologies. It is not surprising that now, concern for the quality of teaching and the implementation of new methodological and pedagogical processes is a constant in all European educational systems. A good part of the efforts of the authorities responsible for them is dedicated to realizing the challenge that both the Organization for Economic Cooperation and Development (OECD) and the European Union (EU) itself have summarized in three words: attracting, training and retaining effective teachers. Thus, the experts claim the need to guarantee conditions related to the attitudes and interpersonal skills of future teachers where practical skills, knowledge, motivations, ethical values, and emotions are combined and a system characterized by its transversely, dynamism, and its integral character [10].

These premises will enable the adoption of new methodological paradigms in the classroom that allow teachers to plan their activity by offering diverse teaching methods. These methodologies guarantee the acquisition of a series of competencies that lead them to abandon the linear process of programming based on objectives, in favor of an updated vision of what it means to teach [11]. Thus, the main transformation we are facing today is the change in the role of students that must pass from observing 
passively to leading their own teaching-learning process. The amount of learning that takes place outside the classroom due to new technologies has made students become an active subject in this process, and see themselves as creators of information and ideas, as well as a consumer of these.

There are multiple sources to stop and delve into to understand how new advances in education and pedagogy are developing [12,13], and growing if we unite education and technology [14-16] observing that the pedagogical and methodological principles prevailing in the 21st century must be based on Personalization by turning school activities into meaningful and authentic experiences. These activities are based on their own needs and learning rhythms with a vision of education that goes beyond the acquisition of specific knowledge or skills, and that can be configured as creative, divergent, and open activities. Active participation where it is about interacting through collaborative methodologies, inter-level, and open to the participation of teachers and students from any part of the world in the planning and development of the educational process where intellectual risks must be assumed. Productivity, as an element that implies overcoming the physical and organizational limits of the classroom through the union of formal and informal learning contexts, taking advantage of global resources and tools, and disseminating the results of the student globally, extrapolating what is studied and learned to everyday life situations.

There are different approaches and new patterns of learning and teaching, giving to the community examples and implementations of new didactic approaches for working with students and with diversity in the classroom [17], whatever its origin. Among them, we can highlight the effect of motivation on learning, self-efficacy, and blended learning on student success. All this from the hand of technology that has fostered both the appearance and the advancement and transformation of other existing methodologies. Likewise, technology has generated new learning spaces, as well as its diffusion throughout the world $[3,7,8]$. With all that said, scientific and political reasons justify our interest in proposing, through this research, an analysis regarding the bibliometric level and the evolution of scientific production.

\section{Aims of the Research}

Usually, science follows a growing process that increases our knowledge on a subject; that is, science is cumulative. Therefore, it must be known what is written and how the research topics that are worked on typically evolve [18]. This type of literature review seeks to detect, achieve, and consult the bibliography and other materials that could be useful for the study [19]. To know a research topic and its evolution implies knowing it's most relevant and publications and how it has evolved over the years [20].

This research aims to search and analyze the terms "Active Methodologies" (and the derivations of the morpheme, using * option). The search has been carried out within the scientific publications in the Web of Science (WoS) database.

After having carried out the search process on the studies that have covered these concepts, they have been analyzed from a bibliometric perspective. This research 
acquires an exploratory nuance and contributes to reducing the gap caused by the absence of scientific publications about this topic. Moreover, the results and conclusions found in this work can serve as the basis and as a start point for future researches, and it can foster the interest of members of the scientific community in this field of knowledge.

To conclude, this research aims to analyze the overall projection of such terms in the scientific WoS database. The specific aims to conduct the research are:

- To know the scientific production of the concepts "active methodologies" and "education" in the WoS database

- To analyze the scientific evolution of "active methodologies" and "education" in the WoS database

- To specify the most highlighted topics about "active methodologies" and "education" in the WoS database

- To find out the most productive and influential authors about "active methodologies" and "education" in the WoS database

\section{$3 \quad$ Materials and Method}

\subsection{Research design}

A bibliometric methodology was conducted to achieve the aims proposed for this research. This has been done using scientometrics to search, report, record, analyze, and predict the scientific productions [21]. This research has been carried out following experts in documentary analysis [22].

Different analytical techniques were used to carry out this research, such as scientific mapping, the quantification of bibliometric indicators (language, publication date, publication area, type of document, organizations, authors, sources, countries, and citations), and the structure and dynamic development of the terms. To proceed with an effective analytical structure and presentation of the results found, previous studies, which have followed this type of research design, have been analyzed too. These studies are found among the impact literature indexed in the Journal Citation Reports (JCR) [23-25].

In clarification, this research has been based on an analysis of co-words and authors [23], thus, applying certain academic indices to establish academic performance (h, g, hg, q2) [26]. This type of study has been chosen for being an innovative method of documentary analysis that is having a great projection in the field of education [2729]. This will help to generate maps with nodes that will be able to establish the position and the performance of the subdomains of the analyzed constructs. Finally, these actions will allow determining the thematic development of the established terms [30]. 


\subsection{Procedure and data analysis}

Different procedures were carried out to do this research: a) Selection of the database; b) Establishment of the keywords to analyze; c) Preparation of the search equation ("Educational") AND ("innovation"); d) Searching with the equation in the WoS search field under the TOPIC tag, to specify in the documents title, abstract and keywords of the existing production.

These actions reported an initial figure of 2578 scientific documents that span from the year 2000 to 2019. Publications of the year 2020 were not taken into consideration as the year had not ended yet and including them could lead to a bias in the investigation. 558 documents were deleted due to the duplication of them or indexing errors, they had. Finally, the research was carried out with an analysis unit of 2208 documents.

These actions were carried out following the protocols of the PRISMA-P matrix for the scientific literature reviews. This protocol has been chosen to follow a model validated by the scientific community that includes a set of standardized items to collect information from publications and avoid biases in the analysis process [31]. This led to the creation of a flow diagram (figure 1).

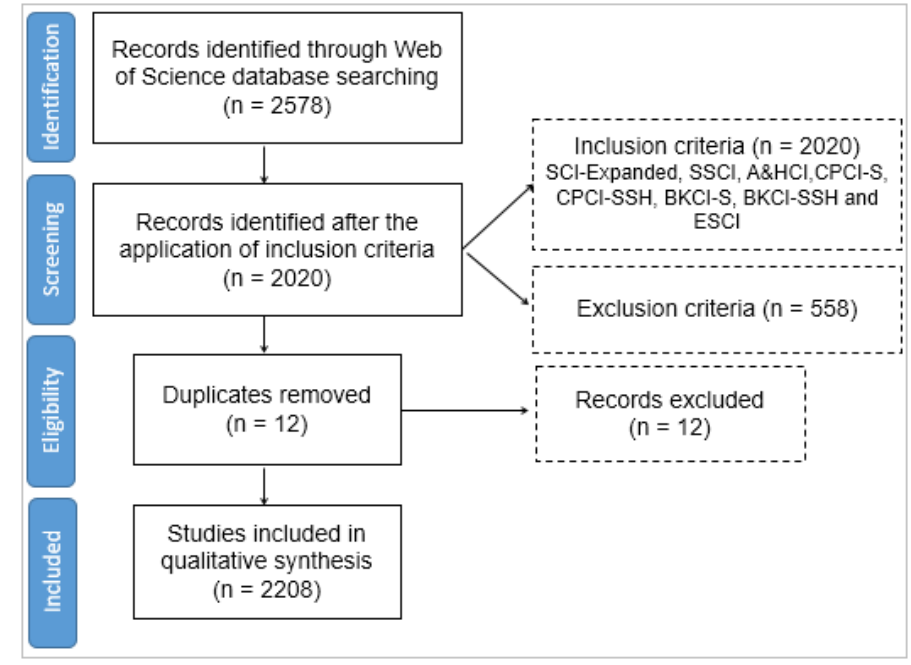

Fig. 1. Flowchart according to the PRISMA Declaration.

Several tools were used to conduct the analysis of the production abovementioned, such as Analyze Results, Creation Citation Report, and SciMAT. The first two ones are offered by the WoS on its own platform. They allow the extraction and even the analysis of data per year, authors, countries, types of documents, institutions, languages, and even medium and most cited documents. Regarding SciMAT, a software which analyzes scientific production, taking into account the words longitudinally and considering their structural and dynamic development. Experts, which have used this tool, were followed to be able to carry out an accurate, efficient, and effective analysis 
[32]. SciMAT allowed the recognition, reproduction, determination, and performance processes of the documents, which are detailed below:

- Recognition: within this process, the publications' keywords were analyzed $(\mathrm{n}=$ 5512). A co-occurrence node map and a standardized network of co-words were done. This was done through a keyword debugging, thus analyzing 4991, finally. At last, the most incidental topics and concepts were established through a clustering algorithm.

- Reproduction: within this process, the creation of a strategic diagram and a thematic network was based on the principles of centrality and density. Four areas were specified in the originated graphs whose particularities are detailed in motor and important issues (upper right area), isolated and entrenched issues (upper left area), and issues that are projected or are disappearing (lower left area) and issues with a low and transversal level of development (lower right area).

- Determination: within this process, the created nodes corresponded to the different periods $(\mathrm{P})$ or time intervals, which were analyzed. For the co-words study, five periods were configured, following as a criterion 500 documents per period. The common keywords between such periods create the strength of association.

- Performance: This process obtained the reported connections between the keywords and other concepts that determine the trend of the nodes. For this, various production indicators were established along with their respective inclusion criteria. Specifically, this process covered several protocols: 1-Analysis unit refers to the study sample. In particular, it refers to the keywords determined by both the authors and WoS in each of the publications; 2-The frequency threshold delimits the minimum threshold for each period, based on the keywords of the recovered documents; 3-Network type refers to the type of network that is going to be formed. In this study, a network of co-occurrence of keywords is elaborated; 4-Co-occurrence union value threshold determines the configured periods; 5-The normalization measure determines the threshold of union or minimum connection for the occurrence. The normalization of the network was produced by the equivalence index eij $=$ cij2 / Root (ci - cj); 6-The clustering algorithm allows to generate the associations between the themes or subnets of the maps. Specifically, the simple centers algorithm has been used; 7-The evolutionary measure determines the similarity necessary to prepare the evolution map that was made using the Jaccard index and the transition map using the inclusion rate as an overlapping measure (table 1).

Table 1. Production indicators and inclusion criteria.

\begin{tabular}{|l|l|}
\hline \multicolumn{1}{|c|}{ Configuration } & \multicolumn{1}{c|}{ Values } \\
\hline Analysis unit & Keywords authors, keywords WoS \\
\hline Frequency threshold & Keywords: $\mathrm{P}_{1}=(3), \mathrm{P}_{2}=(4), \mathrm{P}_{3}=(5), \mathrm{P}_{4}=(6), \mathrm{P}_{5}=(6)$ \\
\hline Network type & Co-occurrence \\
\hline Co-occurrence union value threshold & Keywords: $\mathrm{P}_{1}=(2), \mathrm{P}_{2}=(2), \mathrm{P}_{3}=(2), \mathrm{P}_{4}=(2), \mathrm{P}_{5}=(2)$ \\
\hline Normalization measure & Equivalence index \\
\hline Clustering algorithm & Maximum size: $9 ;$ Minimum size: 3 \\
\hline Evolutionary measure & Jaccard index \\
\hline Overlapping measure & Inclusion Rate \\
\hline
\end{tabular}




\section{$4 \quad$ Results}

Among the 2208 publications retrieved, there are 3,311 affiliations and 5,422 authors from 82 countries. Figure 2 shows the statistical results of the diachronic evolution of production

a) The countries with the highest production

b) The most productive authors

c) The main areas of research

About the evolution of production throughout these years, a positive trend is shown from 2000 to 2014. Afterward, this growth trend is changing, highlighting the production of 2017 with 342 documents. Regarding the main language in which the documents are available, it is English (60\%), followed by Spanish (39\%). Many documents are published in both languages (English and Spanish). Regarding the most productive authors on the subject, SEIN-ECHALUCE ML, GARCIA-PENALVO FJ., and FIDALGO-BLANCO A. stand out with 11 documents each one.

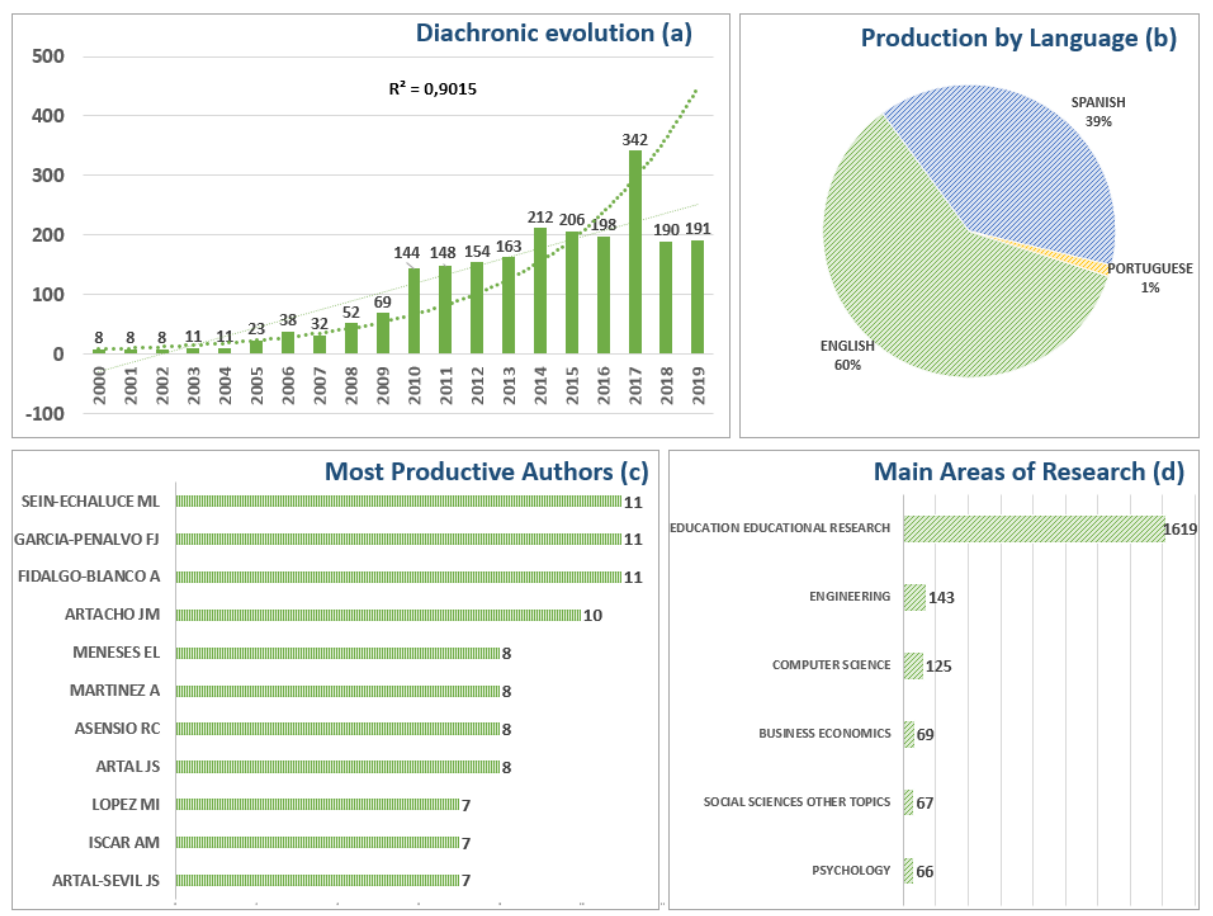

Fig. 2. Diachronic evolution of production (a), production by language (b), the most productive authors (c), and main areas of research (d). 


\subsection{Development of thematic analysis}

It is necessary to use the frequency of the concurrence of the words of a text to build a thematic network. Later they are grouped using a simple center algorithm, one of the most efficient in the scientific literature [33,34]. In this case, the most representative word of a source are the keywords proposed by authors.

For each time, two types of strategic diagrams have been generated to analyze the most prominent themes. The size of the sphere in the first diagram is proportional to the count of posts associated with each topic, while in the second, the size of the sphere is proportional to the count of citations received for each topic. We divide the 20 years into five periods, that is, [2000-2010], [2011-2013], [2014-2015], [20162017] and [2018-2019].

Figure 3 shows the evolution of the keywords throughout the analyzed period and the number of words that are extracted from one period inside. Among all the periods analyzed, there are coincidence levels of less than $30 \%(<0.30)$, which shows that the thematic areas worked on have been different, have not been maintained over time, or that the variety of lines of research has been quite wide.

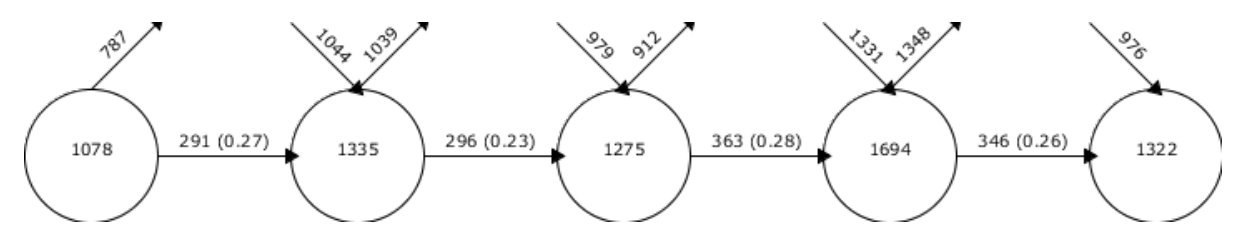

Fig. 3. Keywords continuity between intervals.

The main themes identified, obtained based on the established time intervals, are shown (Table 2) based on the classic bibliometric indicators (h-index, g-index, hgindex, q2-index). In this case, in the first period (P1) it is observed that the keyword with the highest $\mathrm{H}$ index is "HIGHER-EDUCATION", with a value much higher than that found in the second word, "INNOVATION". For the second time range (P2), the word with the highest $\mathrm{H}$ index is again "HIGHER-EDUCATION", in this case, followed by the terms "EDUCATION" and "USA". For the second time range (P2), the word with the highest $\mathrm{H}$ index is again "HIGHER-EDUCATION", in this case, followed by the terms "EDUCATION" and "USA". For the third period, we find "EDUCATIONAL-INNOVATION" first, followed by "EDUCATION", a term that is maintained from the previous period. In the fourth period (P4) we find "MOTIVATION" first, followed by "STUDENTS". For the last period (P5), the topic with the highest $\mathrm{H}$ index is "EDUCATIONAL-INNOVATION" closely followed by "IMPACT." 
Table 2. Classic bibliometric indicators (h-index, g-index, hg-index, q2-index) for analyzed periods.

\begin{tabular}{|c|c|c|c|c|c|c|}
\hline \multicolumn{7}{|c|}{ 2000-2010 Period } \\
\hline & Docs & H Index & G Index & Hg Index & $Q^{2}$ Index & Cites \\
\hline HIGHER-EDUCATION & 40 & 9 & 17 & 12.37 & 13.08 & 328 \\
\hline INNOVATION & 9 & 5 & 5 & 5 & 8.37 & 129 \\
\hline MOTIVATION & 3 & 3 & 3 & 3 & 10.82 & 240 \\
\hline CLASSROOM & 3 & 3 & 3 & 3 & 5.48 & 99 \\
\hline COMPETENCES & 4 & 1 & 2 & 1.41 & 2.83 & 9 \\
\hline \multicolumn{7}{|c|}{ 2011-2013 Period } \\
\hline & Docs & H Index & G Index & Hg Index & $Q^{2}$ Index & Cites \\
\hline EDUCATION & 18 & 4 & 7 & 5.29 & 10.77 & 107 \\
\hline HIGHER-EDUCATION & 29 & 6 & 11 & 8.12 & 6.93 & 153 \\
\hline USA & 7 & 4 & 6 & 4.9 & 6.93 & 53 \\
\hline TECHNOLOGY & 7 & 3 & 4 & 3.46 & 4.9 & 26 \\
\hline ICT & 6 & 2 & 4 & 2.83 & 4 & 19 \\
\hline ECTS & 4 & 1 & 1 & 1 & 1 & 1 \\
\hline \multicolumn{7}{|c|}{ 2014-2015 Period } \\
\hline & Docs & H Index & G Index & Hg Index & $Q^{2}$ Index & Cites \\
\hline EDUCATIONAL-INNOVATION & 71 & 9 & 17 & 12.37 & 14.7 & 374 \\
\hline EDUCATION & 14 & 6 & 12 & 8.49 & 9.8 & 158 \\
\hline ICT & 7 & 1 & 1 & 1 & 2 & 4 \\
\hline TECHNOLOGY & 9 & 3 & 4 & 3.46 & 3.46 & 16 \\
\hline ACTIVE-LEARNING & 4 & 1 & 1 & 1 & 1.41 & 5 \\
\hline \multicolumn{7}{|c|}{ 2016-2017 Period } \\
\hline & Docs & H Index & G Index & Hg Index & $Q^{2}$ Index & Cites \\
\hline MOTIVATION & 16 & 5 & 9 & 6.71 & 6.32 & 91 \\
\hline STUDENTS & 17 & 4 & 8 & 5.66 & 6 & 73 \\
\hline EDUCATIONAL-INNOVATION & 50 & 4 & 5 & 4.47 & 5.29 & 65 \\
\hline ACTIVE-LEARNING & 14 & 1 & 1 & 1 & 4.8 & 23 \\
\hline \multicolumn{7}{|c|}{ 2018-2019 Period } \\
\hline & Docs & H Index & G Index & Hg Index & $Q^{2}$ Index & Cites \\
\hline EDUCATIONAL-INNOVATION & 90 & 4 & 5 & 4.47 & 4 & 68 \\
\hline INNOVATION & 13 & 1 & 1 & 1 & 1 & 2 \\
\hline SCIENCE & 5 & 1 & 1 & 1 & 1.41 & 3 \\
\hline IMPACT & 6 & 3 & 3 & 3 & 3.46 & 18 \\
\hline
\end{tabular}

The detected networks can be represented by two measures, that is, the centrality and the density of Callon. The Callon centrality index measures the degree of interaction between networks. The internal strength of the network can be measured by the density defined as internal links between all the keywords that are grouped around a specific topic. The analysis of the diagrams proposed shows a clear trend in the first two periods, with those studies related to "Higher Education" prevailing. In the third and fourth periods, "technology" and "motivation" stand out as the main themes. Another of the themes that you have talked about in the different periods is "Educational innovation." 
Carrying out a deeper analysis of the main themes of each period we found that, for period 1, the topic with the most impact is HIGHER EDUCATION, which focuses its studies on "sustainable development," "e-learning" and "sustainability," "e-portfolio," "Educational innovation," "Information technology," "active learning" and "academic performance." For period 2, the main topic with the most impact is HIGHER EDUCATION, in which the research is related in this case to "community", "teamwork," "action research," "Blended learning," "reform," "organizations "in addition to" Educational innovation," "Information technology." For P3, the driving theme is again, EDUCATIONAL INNOVATION. In this case, the topics that govern these researches are centered on "Higher Education", "Learning by doing", "E-learning", engineering education," "motivation," "information technology" and ICT. For period 4 , the term with the most impact is MOTIVATION, whose guiding themes are "higher education," "Performance," "Gamification," "Blended Learning," "Achievement," "engineering education," "E-learning" and "Learning by doing." For the last period, the trend seems to be similar to that of period 3, with EDUCATIONAL INNOVATION being the main theme, in this case, the main themes that guide the research are "performance," "ICT," "Gamification," "Schools," "Students," "Gamification," "engineering education," "Higher Education" (figure 4).

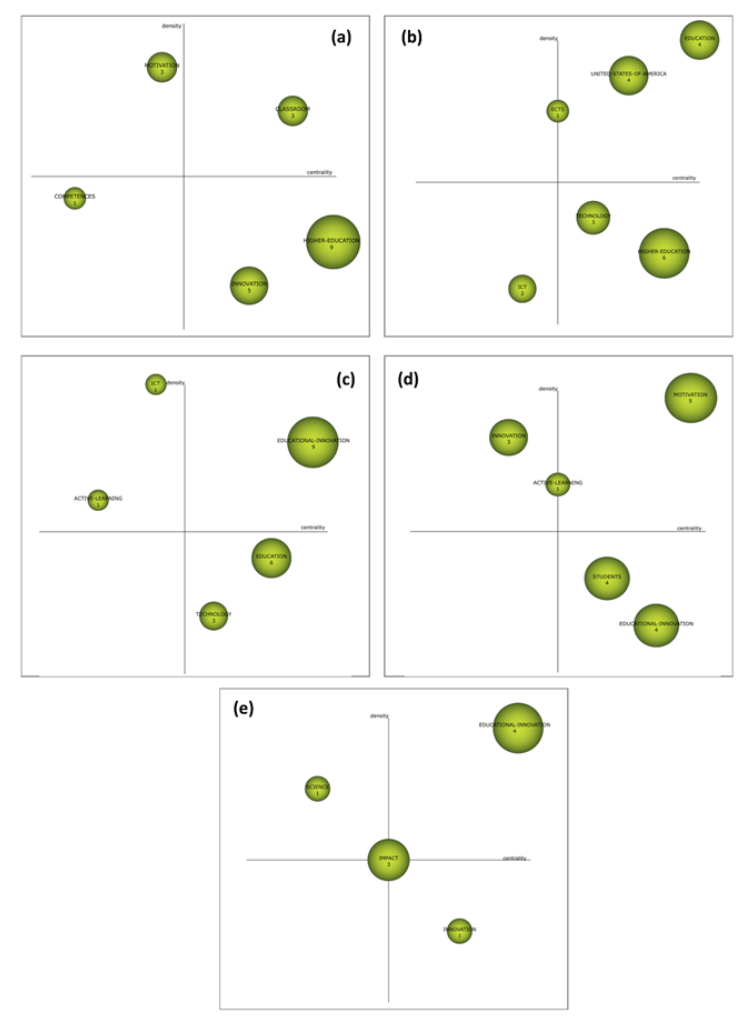

Fig. 4. Strategic diagram of h index. (a) Interval 2000-2010; (b) Interval 2011-2013; (c) Interval 2014-2015; (d) Interval 2016-2017; (e) Interval 2018-2019 


\subsection{Thematic evolution}

The thematic evolution allows us to study the relationships between the themes worked over different periods, through conceptual links (solid line) or non-conceptual links (stitched lines). The thickness of them indicates the strength of these relationships, following the results of figure 5. On the other hand, the size of the sphere represents the index $\mathrm{h}$ of the documents that belong to each topic. The shades of colors bring together the labeled subjects within the same thematic area.

The scientific production analyzed is characterized by being varied, a main pattern is observed between the different periods. Although at the beginning, the investigations were exclusively focused on a higher education field, this topic has been losing strength. In the last two periods, the topics centered on students ('STUDENTS'), active learning ('Active learning'), educational innovations in general ('Educational innovation'), and those developed in the field of science stand out. Although it is not a topic that has followed a standard evolution of the literature, the last section shows the potential for dissemination of those studies that show the impact of this type of methodology in the educational field.

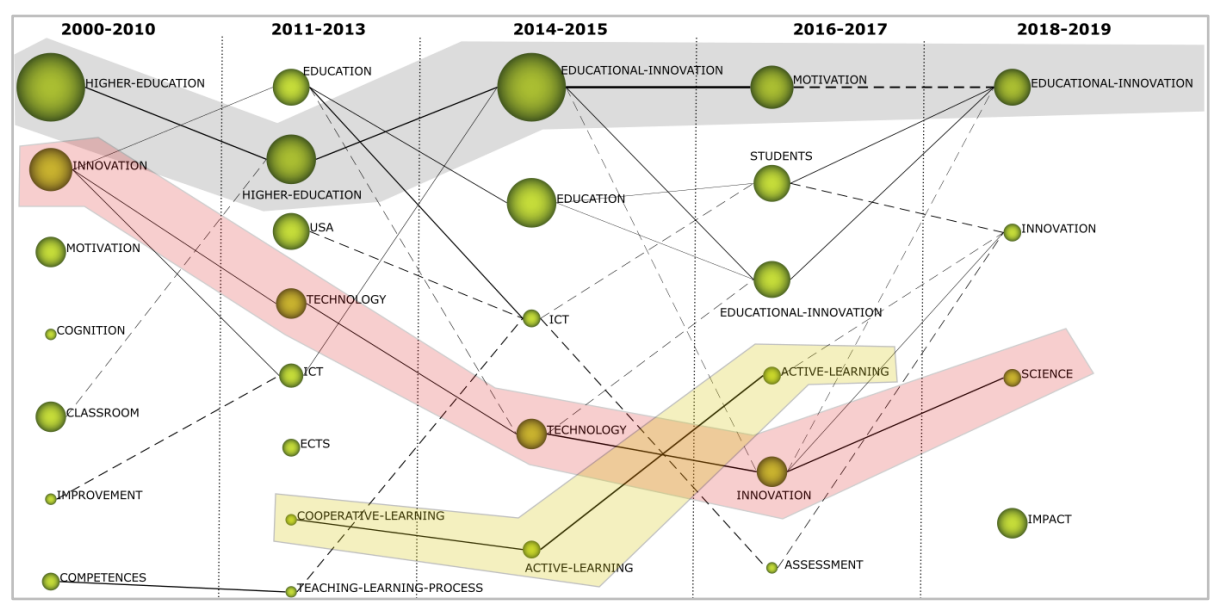

Fig. 5. Thematic evolution of the analyzed area 2000-2019.

\section{$5 \quad$ Discussion and Conclusion}

The importance of this study is that there is no other research about these terms and therefore, it is original and gives the scientific community the knowledge and information about this field. Despite this, it has followed the technical view, in several parts of the research, of other studies which have done a literature review and are well situated among the researches of this category [18,19,24,25].

Nowadays, teaching has become a space for sharing content in an interactive way, where the student assumes a leading role and becomes an active person in the learning process [4]. The situation that teaching is going through requires that education pro- 
fessionals have a series of technological competences and skills, in addition to a solid training in the theoretical content of the subject they teach, to adapt the means, forms, tools, and channels to spread knowledge [5]. These training practices lead to teaching innovation to find new ways to develop their profession adjusted to the technopedagogical paradigms of today's society, characterized by rapid access to information from any electronic medium [8].

The information which reflected in the existing literature on the state of the question reveals a growing projection on studies related to innovation in education. The data shows a positive and growing evolution, with 2017 being the most prolific year of all so far. In these studies, the English language predominates mainly, something classic in scientific literature, since it is the official language of most of the journals indexed in WoS [32]. Only about a third of the production is written in Spanish. Regarding the area in which these publications are collected, it stands out above the rest Education Educational Research, as a category that indexes studies concerning the educational field in which the analyzed research focuses Sein-Echaluce, M.L., GarciaPenalvo, F.J. and Fidalgo-Blanco, A. are the most productive researchers on this topic.

The study of the keywords, of the reported production of the different configured periods, shows how the topics investigated have been diverse. Specifically, the first period focuses on Higher Education, followed by Innovation. The second period repeats Higher Education, accompanied by Education and USA. The third period focuses on Educational Innovation and Education, just like the predecessor period. Motivation and Student have more publications in the fourth period. Moreover, in the last and fifth-most current period, Educational Innovation reappears together with Impact.

In the different periods in which the motor themes are repeated, these highlights have undergone internal variations such as the case of Higher Education. In the first period, it included concepts such as "sustainable development," "e-learning" and "sustainability," "e-portfolio," "Educational innovation," "Information technology," "active learning" and "academic performance." In contrast, in the second period, it focuses mainly on "community," "teamwork," "action research," "Blended learning," "reform," "organizations," as well as "Educational innovation," and "Information technology."

Regarding the evolution of the topics in this diverse scientific production, it was initially characterized by dealing with aspects related to Higher Education. This finding is in analogy with what $[35,36]$ expounded. However, over the years, this topic has been decreasing the volume of production to give way in other periods to research focused on students, active learning, educational innovation with a generic character, and the scientific field of innovation. It also highlights the impact of innovation, as a topic that is being analyzed by researchers in recent years.

It is concluded that the scientific production on educational innovation has been in positive projection from the beginning of its origin to the present day. English stands out as the main language in the writing of publications. Also, there is a glimpse of a variety of themes throughout the course of research on educational innovation at WoS, initially focused on Higher Education, until today with themes focused on the 
active action of the student and the impact that the innovation involves in learning environments.

The purpose of this study is based on making known to researchers interested in the subject the importance that educational innovation has had throughout its journey through the scientific literature, as well as revealing the topics covered in the different articulated periods. All this to offer the scientific community those booming topics on which the current state of the issue addressed in the present work is based.

This research has presented different limitations. Only one database (WoS) has been used, so the results shown reflect only one perspective of the scientific literature. On the other hand, the configuration of the periods in which the scientific production has been grouped has been made at the discretion of the researchers, so that each interval brings together a similar volume of publications. Also, the purification of the reported data from WoS to carry out the final analysis of the publications also implies the particular decision of the researchers, as well as the establishment of certain exclusion criteria.

As a future line of research, the aim is to analyze the scientific production on educational innovation linked to the most prominent themes in recent years. All this to carry out a meta-analysis of the existing literature that supports the basic knowledge of these booming topics.

\section{References}

[1] O. Rodríguez and P. M. Concepción, "La integración escuela-familia-comunidad: un reto para la educación contemporánea”. Educación y Sociedad, Vol. 1, no. 18, pp. 70-80, 2020.

[2] D. Pareja de Vicente, J.J. Leiva Olivencia and A. Matas Terrón, "Percepciones sobre diversidad cultural y comunicación intercultural de futuros maestros". Revista Electrónica Interuniversitaria de Formación del Profesorado, Vol. 1, no. 23, pp. 75-87, 2020. https:// doi.org/10.6018/reifop.403331

[3] Z. Nurbekova, V, Grinshkun, G, Aimicheva, B, Nurbekov and K. Tuenbaeva, "ProjectBased Learning Approach for Teaching Mobile Application Development Using Visualization Technology”. IJET, Vol. 8, no. 15, pp. 130-143, 2020. https://doi.org/10.3991/ijet. v15i08.12335

[4] S. Cheon, J. Reeve and M. Vansteenkiste, "When teachers learn how to provide classroom structure in an autonomy-supportive way: Benefits to teachers and their students". Teaching and Teacher Education, no. 90, 2020. https://doi.org/10.1016/j.tate.2019.103004

[5] S. Bradley and C. Green, The economics of education. A Comprehensive Overview. Academic press. 2020. https://doi.org/10.1016/C2017-0-02304-2

[6] C. Scott, El futuro del aprendizaje; ¿qué tipo de aprendizaje se necesita en el siglo XXI? Organización de las naciones unidas. 2015.

[7] D. Scaradozzi, L. Screpanti, L. Cesaretti, M. Storti and E. Mazzieri, "Implementation and assessment methodologies of teachers' training courses for STEM activities". Technology, Knowledge and Learning, Vol. 24, no. 2, pp. 247-268, 2019. https://doi.org/10.1007/s107 58-019-09406-9 https://doi.org/10.1007/s10758-018-9356-1

[8] S. Wichadee, "A development of the blended learning model using edmodo for maximizing students' oral proficiency and motivation”. iJET, Vol. 2, no. 12, pp. 137-154, 2017. https://doi.org/10.3991/ijet.v12i02.6324 
[9] V. Marín-Díaz and B. E. Sampedro-Requena, "La Realidad aumentada en Educación Primaria desde la visión de los estudiantes”. Alteridad, Vol. 1, no. 15 pp. 61-73, 2020. https:// doi.org/10.17163/alt.v15n1.2020.05

[10] E. Pulham and A. C. R. Graham. "Comparing K-12 online and blended teaching competencies: a literatura review”. Distance Education, Vol. 39, no. 3, pp. 411-432, 2018. https:// doi.org/10.1080/01587919.2018.1476840

[11] S. Deliligka, I. Syrmpas and A. Bekiari, "Motivational Climate in the Physical Education Context through the Perspective of Teachers and Students". Physical Educator, Vol. 1, no. 77, pp. 78-109, 2020. https://doi.org/10.18666/tpe-2020-v77-i1-8524

[12] P. Rios and A. Vieira, "The emerging of a gender discourse in education: the differences in the school space". Tempos e Espaços em Educação. vol. 13, no. 32, pp.1-17, 2020. https://doi.org/10.20952/revtee.v13i32.13061

[13] M. Kultaieva, N. Radionova, O. Ivastchenko and N. Grigorova, "Representación en prácticas educativas: afirmaciones reales y replanteamiento de la tradición pedagógica". Dilemas Contemporáneos: Educación, Política y Valores, no. 7, pp. 1-14, 2020. https://doi.org/10.46377/dilemas.v33i1.2181

[14] J. Adell, M. Llopis, F. Esteve and M. Valdeolivas, "El debate sobre el pensamiento computacional en educación". RIED. Revista Iberoamericana de Educación a Distancia, Vol. 1, no. 22, pp. 171-186, 2019. https://doi.org/10.5944/ried.22.1.22303

[15] A. Bartolomé, L. Castañeda and J. Adell, "Personalisation in educational technology: the absence of underlying pedagogies". International Journal of Educational Technology in Higher Education Vol. 1, no. 15, p. 1-17, 2018. https://doi.org/10.1186/s41239-018-0095-0

[16] L. Castañeda and N. Selwyn, "More than tools making sense of the ongoing digitizations of higher education". International Journal of Educational Technology in Higher Education, Vol. 1, no. 15, p. 1-10, 2018. https://doi.org/10.1186/s41239-018-0109-y

[17] R. Rafiola, P. Setyosari, C. Radjah and M. Ramli, "The Effect of Learning Motivation, Self-Efficacy, and Blended Learning on Students' Achievement in The Industrial Revolution 4.0". IJET, Vol. 8, no. 15, pp. 71-82, 2020. https://doi.org/10.3991/ijet.v15i08.12525

[18] A. Durán-Sánchez, J. Álvarez-García, M. de la Cruz del Río-Rama and E. GonzálezVázquez, "Literature Review of Wine Tourism Research: Bibliometric Analysis (19842014)," in Wine and Tourism, M. Peris-Ortiz, M. de la C. Del Río Rama and C. RuedaArmengot, Eds. Cham: Springer International Publishing, 2016, pp. 257-273. https://doi. org/10.1007/978-3-319-18857-7 18

[19] R. Hernández-Sampieri, C. Fernández-Collado, P. Baptista-Lucio, S. Méndez-Valencia and C. P. Mendoza-Torres, Metodología de la investigación, 1st ed. Mexico, D.F.: McGrawHill, 2014.

[20] H. F. Moed, Applied evaluative informetrics. Cham: Springer, 2017.

[21] M. A. Martínez, M. J. Cobo, M. Herrera and E. Herrera-Viedma, "Analyzing the Scientific Evolution of Social Work Using Science Mapping". Research on Social Work Practice, Vol. 2, no. 25, pp. 257-277, 2015. https://doi.org/10.1177/1049731514522101

[22] J. A. Moral-Muñoz, E. Herrera-Viedma, A. Santisteban-Espejo and M. J. Cobo, "Software tools for conducting bibliometric analysis in science: An up-to-date review". El Profesional de La Información, Vol. 1, no. 29, pp. 1-20, 2020. https://doi.org/10.3145 lepi.2020.ene. 03

[23] P. Hallinger and J. Kovačević, "A bibliometric review of research on educational administration: Science mapping the literature, 1960 to 2018". Review of Educational Research, Vol. 89, no. 3, pp. 335-369, 2019. https://doi.org/10.3102/0034654319830380

[24] J. López-Belmonte, A. Segura-Robles, A. J. Moreno-Guerrero and M. E. Parra-González, "Machine Learning and Big Data in the Impact Literature. A Bibliometric Review with 
Scientific Mapping in Web of Science". Symmetry, Vol. 4, no. 12, pp. 1-15, 2020. https:// doi.org/10.3390/sym12040495

[25] M. E. Parra-Gonzalez and A. Segura-Robles, "Scientific production on gamification in education: a scientometric analysis". Revista de Educación, Vol. 386, no. 5, pp. 113-131, 2019. https://doi.org/10.4438/1988-592X-RE-2019-386-429

[26] J. E. Hirsch, “An index to quantify an individual's scientific research output”. Proceedings of the National Academy of Sciences, Vol. 46, no. 102, pp. 16569-16572, 2005. https://doi. org/10.1073/pnas.0507655102

[27] M. J. Cobo, A. G. López-Herrera, E. Herrera-Viedma and F. Herrera, "Science mapping software tools: Review, analysis, and cooperative study among tools". Journal of the American Society for Information Science and Technology, Vol. 7, no. 62, pp. 1382-1402, 2011. https://doi.org/10.1002/asi.21525

[28] E. Herrera-Viedma, J.R. López-Robles, J. Guallar and M.J. Cobo, "Global trends in coronavirus research at the time of Covid-19: A general bibliometric approach and content analysis using SciMAT”. El Profesional de la Información, Vol. 29, no. 3, pp. 1-20, 2020. https://doi.org/10.3145/epi.2020.may.22

[29] A. Segura-Robles, A.J. Moreno-Guerrero, E. Parra-González, E. and J. López-Belmonte, "Review of Research Trends in Learning and the Internet in Higher Education". Social Sciences, Vol. 9, no. 6, pp. 1-16, 2020. https://doi.org/10.3390/socsci9060101

[30] J. R. López-Robles, J. R. Otegi-Olaso, I. Porto Gómez and M. J. Cobo, "30 years of intelligence models in management and business: A bibliometric review". International Journal of Information Management, no. 48, pp. 22-38, 2019. https://doi.org/10.1016/j.ijinfomgt. $\underline{2019.01 .013}$

[31] G. Urrútia and X. Bonfill, "Declaración PRISMA: una propuesta para mejorar la publicación de revisiones sistemáticas y metaanálisis”. Medicina clínica, Vol. 135, no. 11, pp. 507-511, 2010. https://doi.org/10.1016/j.medcli.2010.01.015

[32] J. Montero-Díaz, M. J. Cobo, M. Gutiérrez-Salcedo, F. Segado-Boj and E. HerreraViedma, "A science mapping analysis of 'Communication' WoS subject category (19802013)”. Comunicar, Vol. 55, no. 26, pp. 81-91, 2018. https://doi.org/10.3916/C55-2018-08

[33] J. R. López-Robles, J. Guallar, J. R. Otegi-Olaso and N. K. Gamboa-Rosales, "El profesional de la información (EPI): Bibliometric and thematic analysis (2006-2017)", EPI, Vol. 28, no. 4, pp. 1-24, 2019, https://doi.org/10.3145/epi.2019.jul.17

[34] M. J. Cobo, A. G. López-Herrera, E. Herrera-Viedma and F. Herrera, “An approach for detecting, quantifying, and visualizing the evolution of a research field: A practical application to the Fuzzy Sets Theory field," Journal of Informetrics, Vol. 5, no. 1, pp. 146-166, 2011, https://doi.org/10.1016/j.joi.2010.10.002

[35] É. Archambault, É. Vignola-Gagné, G. Côté, V. Larivière and Y. Gingrasb, "Benchmarking scientific output in the social sciences and humanities: The limits of existing databases". Scientometrics, Vol. 3, no. 68, pp.329-342, 2006. https://doi.org/10.1007/s11192$\underline{006-0115-\mathrm{Z}}$

[36] Y. Liu and J. Fang, "What is The Hot Topic of Graduate Education Research? - A Literature Analysis Based on SSCI Articles in 2015-2019”. In 2019 2nd International Conference on Education, Economics and Social Science (ICEESS 2019). Atlantis Press. https:// doi.org/10.2991/iceess-19.2019.28 


\section{Authors}

$\mathbf{M}^{\mathbf{a}}$ Elena Parra-González is a Spanish $\mathrm{PhD}$, professor and researcher on Educational Sciences University of Granada, Faculty of Education, Economy and Technology, in Ceuta, Spain. Her line of research focuses on educational technology and active methodologies in learning spaces.

Adrián Segura-Robles is a Spanish $\mathrm{PhD}$, professor and researcher on Educational Sciences University of Granada, Faculty of Education, Economy and Technology, in Ceuta, Spain. His line of research focuses on educational technology and active methodologies in learning spaces. He is a reviewer for WOS journals.

Manuel-Ricardo Vicente-Bújez is a professor and researcher at the University of Granada (Spain). He belongs to the Department of Didactics of Musical, Plastic and Body Expression. His line of research focuses on educational technology and active methodologies in learning spaces.

Jesús López-Belmonte is a professor and researcher at the University of Granada (Spain). He belongs to the Department of Didactics and School Organization. He develops his scientific activity in the AREA Research Group (Hum-672). His line of research focuses on educational technology and active methodologies in learning spaces.

Article submitted 2020-05-16. Resubmitted 2020-07-04. Final acceptance 2020-07-05. Final version published as submitted by the authors. 